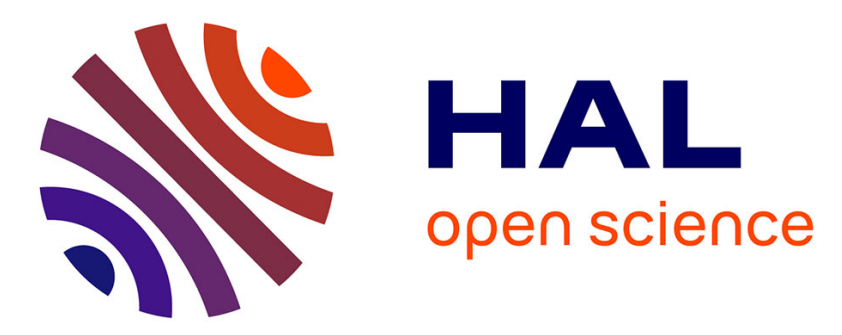

\title{
Influence of cold bending on the resistance of wide flange members
}

Michalis Hadjioannou, Cyril Douthe, Charis J Gantes

\section{To cite this version:}

Michalis Hadjioannou, Cyril Douthe, Charis J Gantes. Influence of cold bending on the resistance of wide flange members. International Journal of Steel Structures, 2013, 13 (2), 14p. 10.1007/s13296013-2013-6 . hal-00937622

\section{HAL Id: hal-00937622 \\ https://hal.science/hal-00937622}

Submitted on 28 Jan 2014

HAL is a multi-disciplinary open access archive for the deposit and dissemination of scientific research documents, whether they are published or not. The documents may come from teaching and research institutions in France or abroad, or from public or private research centers.
L'archive ouverte pluridisciplinaire HAL, est destinée au dépôt et à la diffusion de documents scientifiques de niveau recherche, publiés ou non, émanant des établissements d'enseignement et de recherche français ou étrangers, des laboratoires publics ou privés. 


\title{
Influence of cold bending on the resistance of wide flange members
}

\author{
M.Hadjioannou ${ }^{a}$, C.Douthe ${ }^{b}$, C.J.Gantes $^{c}$ \\ a University of Texas at Austin, Civil, Architectural \& Environmental Engineering Department, Cockrell \\ School of Engineering, U.S.A. \\ ${ }^{b}$ Université Paris-Est, IFSTTAR, France \\ ${ }^{c}$ National Technical University of Athens, School of Civil Engineering, Metal Structures Laboratory, Greece
}

\section{Abstract}

Cold roller bending is commonly used for bending straight members with hot rolled wide-flange sections to create arches. This process induces plastic deformations along the member, so that it can acquire the desired curvature. The resulting residual stress distribution is different from the wellknown residual stress pattern due to hot rolling. Extensive studies have shown that the influence of residual stresses due to hot rolling on the resistance of wide-flange steel sections is non negligible. On the contrary, the residual stress pattern due to roller bending has been only recently clearly identified and its effects on the elasto-plastic behavior of curved members have not been studied sufficiently. Thus, in this paper the influence of such residual stresses on the resistance of both wideflange sections and corresponding arch members is investigated in detail. Taking into consideration the residual stress pattern due to cold bending, interaction diagrams are developed for combined axial load and bending moment, as well as buckling curves for cold bent steel arches. The results are quantified and compared with those for hot-rolled and stress free members. This will allow designers to appreciate the available margins of safety when using standard residual stress pattern for cold bent members. Furthermore, the results suggest the necessity for the development of buckling curves for curved members including initial imperfections. 


\section{Introduction}

Roller bending is nowadays the most common and cost-effective way to produce curved members. Such members are generally made from initially straight hot rolled wide-flange profiles and are used in various structural applications such as arched roofs, atriums and bridges. Roller bending, or cold bending as it is also called, is an iterative process. A straight member passes through three rollers (Figure 1). Plastic deformations are induced at the part of the member which is between the two outer rollers. As the member is rolled all over its length, plastic deformations are induced along the entire length of the member so that it gradually becomes an arch. In each subsequent iteration, the roller in the middle moves vertically towards the other two, in order to increase the curvature. The number of iterations depends on the desired final curvature of the arch. In each pass of the member through the roller, its curvature increases only by small amount. The additional curvature that the member can gain after each pass through the machine is limited due to the local buckling that may occur. In general, as wide-flange sections are prone to local buckling, there are limitations on the maximum curvature that the member can acquire with this process. In order to prevent local buckling of the web, two smaller rollers are sometimes used on the tension flange. They also prevent it from transverse bending known as "Brazier effect" or "ovalization" [1]. A detailed description of the roller bending process has been presented by Bjorhovde [2]. The tension and compression flanges are denoted in this paper as top and bottom flange, respectively (Figure 1).
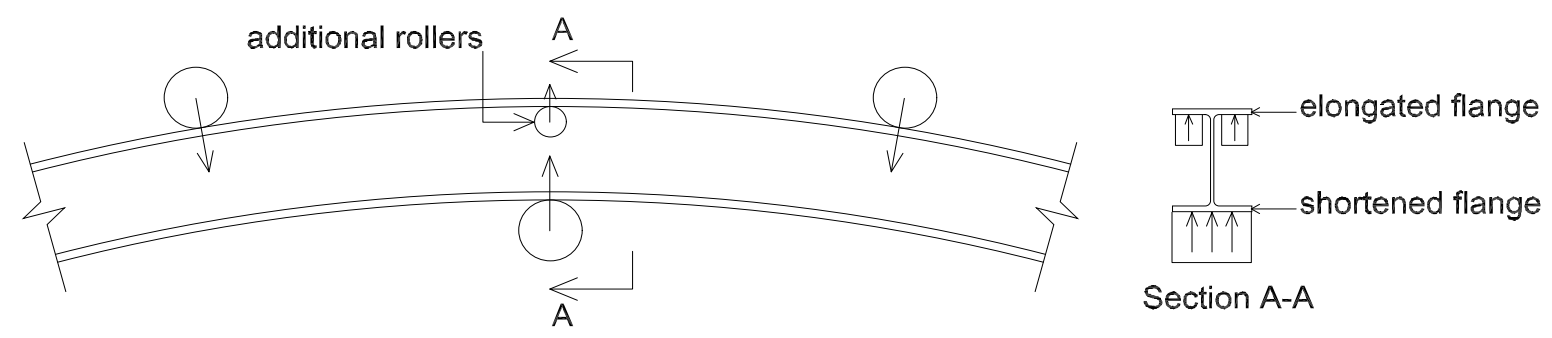

Figure 1: Roller bending process 


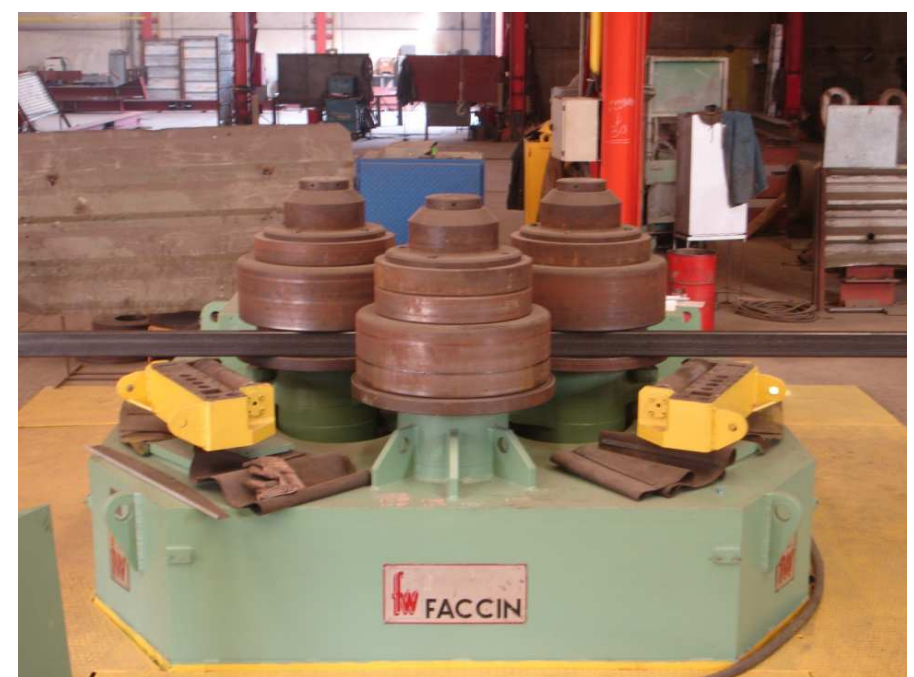

Figure 2: Example of cold curving machine (courtesy EMEK S.A., Greece)

As mentioned above, initially straight hot rolled wide-flange profiles are used for roller bending. It is well known that, due to their manufacturing process, such profiles are not stress free. They have an internally self-equilibrated stress distribution, the so-called residual stresses. Such residual stresses occur due to uneven cooling of the section, i.e. flange tips and middle part of the web tend to cool faster than the other parts of the section. This results in compressive (-) residual stresses at the flange tips and the middle part of the web and tensile $(+)$ stresses at the web to flange junctions.

The residual stress distribution in straight hot rolled wide flange sections is well documented. Various pertinent experiments have been carried out, as presented by Huber and Beedle [3], Beedle and Tall [4], Jez-Gala [5], Mas and Massonet [6], Lay and Ward [7], Galambos [8], Young [9], ECCS [10]. Figure 3 represents the residual stress distribution proposed by Young [9], assuming a parabolic distribution. Specific stress values for this model in $\mathrm{N} / \mathrm{mm}^{2}$ are:

$$
\sigma_{c 1}=-165\left(1-\frac{h t_{w}}{2.4 b t_{f}}\right), \sigma_{c 2}=-100\left(1.5-\frac{h t_{w}}{2.4 b t_{f}}\right), \sigma_{t}=100\left(0.7-\frac{h t_{w}}{2 b t_{f}}\right)
$$

where $\sigma_{c 1}, \sigma_{c 2}$ and $\sigma_{t}$ are the compressive stresses at the tips of the flanges and in the middle of the web, and the tension stress at the intersection of the web to the flanges, respectively. Contrary to other residual stress models, this one suggests that the absolute values of residual stresses are independent of yield stress. In Figure 4 a more simplified residual stress distribution proposed by 
ECCS [10] is illustrated, where linear variation of stresses is assumed while their values depend on the steel grade.

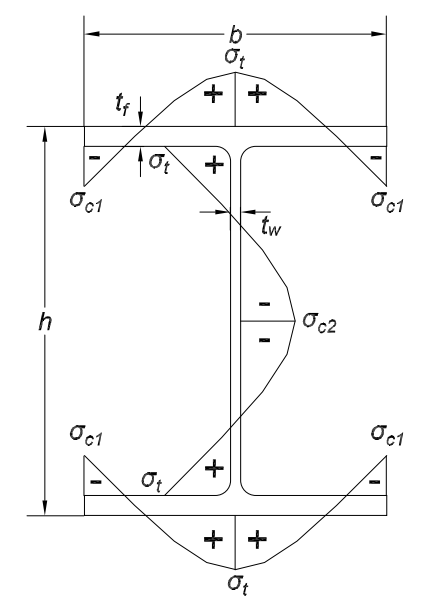

Figure 3: Residual stress distribution due to hot rolling process [9]

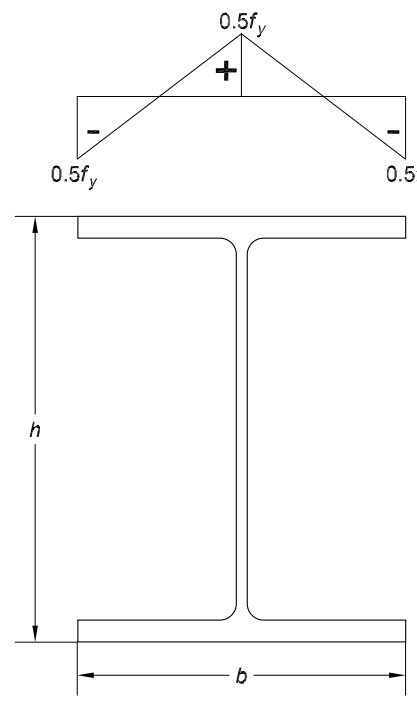

(a) $h / b \leq 1.2$
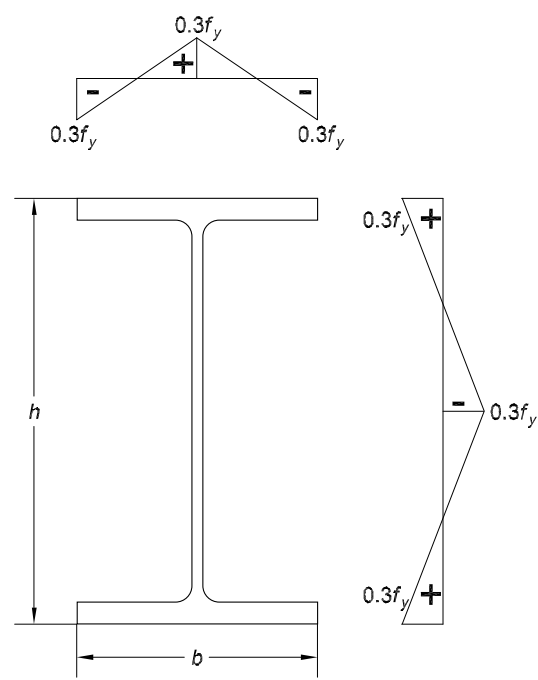

(b) $h / b>1.2$

Figure 4: Residual stress distribution due to hot rolling process [10]: (a) $h / b \leq 1.2$, (b) $h / b>1.2$

The influence of residual stresses due to hot rolling on the behavior and stability of straight members has been investigated in numerous studies [11-14] and was shown to be, in general, not negligible. This is reflected by the inclusion of residual stress models and corresponding buckling curves in various construction standards such as Eurocode 3 [15] and AISC Steel Construction Manual [16]. 
However, when an initially straight member made of hot rolled wide-flange profile is curved into its desired arch shape, the residual stress pattern due to hot rolling is removed and a new, different residual stress pattern due to curving is induced. Studies on the influence of residual stresses on roller bent steel arches have been performed by Komatsu and Sakimoto [17], Sakimoto et al. [18] and Pi and Trahair [19]. However, all these studies were based on a residual stress pattern of straight sections (hot rolling patterns similar to that of Figure 4). However, analytical [20], experimental [21] and computational [22] studies have shown that this is not the actual residual stress distribution in such members. Even if these studies have shown that the influence of material nonlinearities on the resistance of arches is smaller than that of geometric nonlinearities, it must be verified that this is still true for residual stresses induced by cold bending.

Spoorenberg et al. [23] have recently proposed a residual stress pattern especially developed for cold bent wide flange sections. This pattern is based on strong evidence, since the results of detailed experimental [21] and computational [22] studies were combined and included in the proposed residual stress model [23]. However, no studies on the influence of this well defined residual stress model have been performed to evaluate the effects of cold bending in such members. The aim of the present study is hence to evaluate the response of cold bent members with an approach which will be directly applicable to engineering practice. Therefore, the residual stress pattern for cold bent members is used as an initial stress state for an in-depth investigation of the effects of cold bending. Firstly, interaction diagrams are developed for defining the elastic and plastic domain at a section level, following the classical methodology illustrated in [13] for thermally induced residual stresses. Then, considerations on the tangent stiffness of the arched member taking into account these residual stresses are used to evaluate their influence on the member stability. Therefore, buckling curves for perfect circular members are developed. A comparison with properties of hot rolled members is finally conducted, in order to conclude on the necessity or not for developing specific capacity curves for curved members. The comparison also gives quantified results about the 
different influence that cold bent residual stresses have in comparison with hot rolled residual stresses, for which excessive studies have been previously performed.

\section{Residual stresses due to cold bending}

A residual stresses distribution due to cold bending proposed by Timoshenko [20], based on the assumption of a bi-linear material law and employing analytical considerations, is shown in Figure 5, where $\alpha$ is the ratio between the plastic and elastic section modulus, also known as shape factor. A beam model with uniaxial stresses only is used, and therefore no stress gradient is present along the width of the beam and no plate effects are taken into account. A similar model taking into account the curving radius was proposed by the Steel Construction Institute [24].

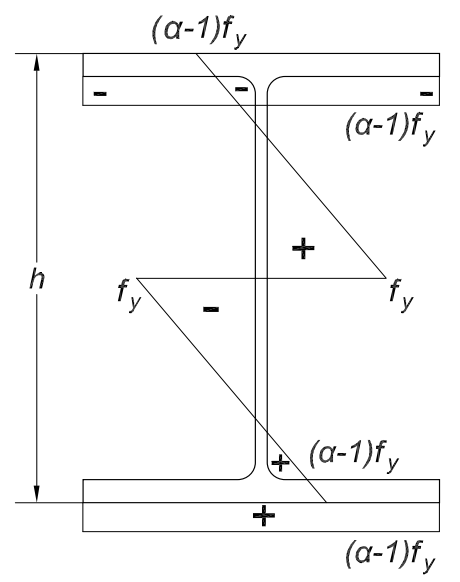

Figure 5: Residual stress distribution for roller bent I-sections proposed by Timoshenko [20]

Further analytical and experimental investigations of the residual stresses in various types of crosssections have then been carried out by Weng and White [25], Weng and Pekoz [26], Tan et al. [27]. Regarding the residual stresses in wide-flange sections, the available experimental data are limited. Spoorenberg et al. [23] have recently carried out an experimental program focusing on the residual stresses due to cold bending on such sections. Using the sectioning method for their measurements, they validated their method by comparing measurements of residual stresses in straight members with the theoretical thermal stresses and reproduced the same method on members after curving. 
They further compared their results with detailed finite element simulations of the roller bending process [22] by explicitly modeling the whole process. In their models they included full interaction between the machine parts, i.e. rollers, and workpiece, i.e. steel section.

Based on these, they proposed a residual stress model for roller bent wide flange sections [23]. Their model is generally applicable within a range of bending radii $10 \leq R / h \leq 40$ and is linearly related to the magnitude of the original yield stress for S235 and S355 steel sections. In this model the residual stress gradients over the web and flange thickness are ignored. For the top flange, a linear stress gradient of $0.2 f_{y}$ tensile stress at the flange tips to $0.2 f_{y}$ compressive stress at the flange center is proposed (Figure 6). For the bottom flange a bi-linear stress pattern is suggested, with a compressive stress of $0.35 f_{y}$ at the flange tips and a maximum of $0.70 f_{y}$ at the flange center. For the web two triangular stress blocks, one tensile and one compressive, are proposed, with the peaks of the triangles at distances of $0.25 h_{0}$ and $0.75 h_{0}$, respectively, from the web-to-flange junction of the top flange. Based on equilibrium conditions the values of these peaks for the tensile and the compressive stress block are:

$$
\sigma_{w r t}=\frac{7 b t_{f}}{30 h_{0} t_{w}} f_{y}, \sigma_{w r c}=-\frac{14 b t_{f}}{30 h_{0} t_{w}} f_{y}
$$

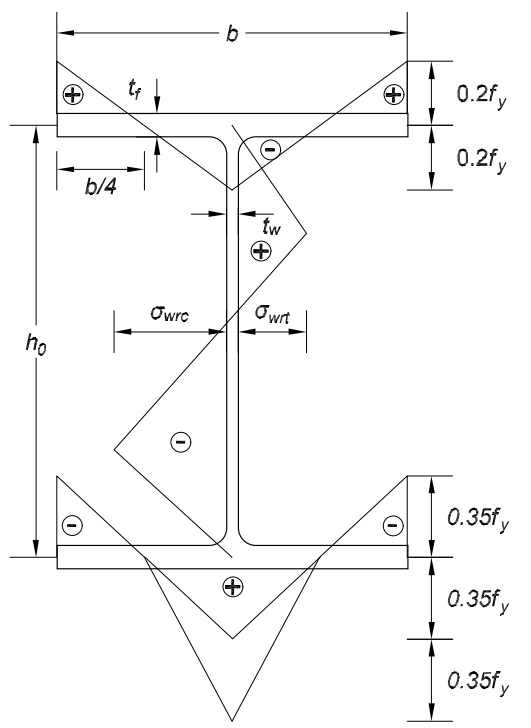

Figure 6: Residual stress model for roller bent wide flange sections proposed in [23] 
Comparing these values with those proposed by Young [28] for straight members, reproduced in Eq.(1), it is noted that in both cases the geometric parameter characterizing the amplitude of residual stresses is the ratio between the flange area $\left(2 b t_{f}\right)$ and the web area $\left(h t_{w}\right)$, and that the magnitude of the residual stresses increases with the ratio $\left(b t_{f} / h t_{w}\right)$. However, stresses due to hot rolling are compressive at the flange tips and midst of the web and tensile at the midst of top and bottom flanges and ends of the web. On the contrary, in roller bent sections, the pattern is antisymmetric about the center of gravity of the section and the signs in both flanges are opposite.

The residual stress distribution proposed by Spoorenberg et al. [23] is well defined, supported by both experimental and numerical results, and it is actually the only residual stress model especially developed for roller bent wide flange sections. It is limited to circular arches curved about their strong axis, it is generally applicable for a certain range of bending radii $(10 \leq R / h \leq 40)$ and it is linearly related to the yield stress of the material law, which is consistent with the theoretical model of Timoshenko [20]. The magnitude and variation of stresses in the two models are however different, particularly in the flanges. This is attributed to the different nature of the two models, as Timoshenko's results are based on a beam model while Spoorenberg's results on a three dimensional solid model. In addition, in [20] the material law is assumed as bilinear and the initial straight member is assumed as stress free. In reality, steel has strain hardening, which is included in the experimental [21] and computational [22] study of Spoorenberg et al.

The "stress jump" at the web-to-flange junctions in [23], namely the different stress values at the top or bottom of the web from the corresponding ones in the middle of the top or bottom flange, is also a cause for concern, although this simplification eases the applicability of the model when it is employed analytically. Moreover, Timoshenko's theoretical model assumes that there is no stress variation over the width of the flanges, which seems unrealistic. Considering the fact that during bending the section undergoes large strains, the assumption that plane sections remain plane may be violated and there may be small changes in the section wall and thicknesses (about 1 or $2 \%$ ). Also, the interaction between the rollers of the bending machine and the members may vary from a 
machine or a section to another and lead to some changes in the presented model. For all these reasons, complementary studies seem necessary and measuring campaigns similar to those for cold formed sections or straight members should be conducted.

\section{Limits of the elasto-plastic domain of roller bent wide flange sections}

In spite of the concerns discussed in the previous section, the residual stress model proposed by Spoorenberg et al.[23] is currently the best available alternative for roller bent wide flange section, thus their pattern shown in Figure 6 is used in this study as an initial stress state for the investigation of the limits of the elasto-plastic domain at a section level and then for the development of buckling curves at a member level. The residual stress model due to hot rolling [10] (Figure 4) is used for comparison. It is assumed that the material is elastic-perfectly plastic, neglecting strain hardening as well as material non-linearities that may be induced by the curving process [29]. Tensile axial forces and moments that tend to open the arch (increase the radius of curvature) and thus act in the opposite direction to the curving moment are denoted as positive $(+)$, while those that tend to close the arch (decrease the radius of curvature) and thus act in the same direction as the curving moment are denoted as negative (-).

\subsection{Determination of the elastic domain}

In the elastic domain, normal stress at any position over the height of the sections is always smaller that the yield stress. Thus, for any combination of normal force $N$ and bending moment $M_{N}$, the total stress, including residual stress (Figure 6), is smaller than $f_{y}$ :

$$
\frac{N}{A}+\frac{M_{N}}{l} z+\sigma_{r s} \leq f_{y}
$$

$A$ and I are the area and moment of inertia of the cross-section, respectively, $\mathrm{z}$ is the distance from the neutral axis (N.A.) of the section, and $\sigma_{r s}$ is the residual stress depending on the position over the height of the section. As all these stresses are linearly distributed over the section, the yield stress will be first reached at one of the peaks or extreme values of the residual stress patterns. Depending 
on the magnitude and direction of normal force and moment, the residual stress peaks at either the web or the flanges may govern first yielding.

\subsection{Determination of the plastic domain}

As for the elastic domain also for the plastic domain, the total stress of the fully yielded section under combined bending and axial force (Figure $7(a)$ ) is the sum of stresses due to applied loads (Figure $7(b)$ ) and residual stresses due to cold bending (Figure $7(\mathrm{c})$ ). It is assumed that the central part of the section undertakes the normal force and the external parts the bending moment. The height of the part undertaking the normal force is denoted as $y_{N}$ and is evaluated from the magnitude of the normal force and the geometrical characteristics of the section. To determine this limit analytically, it must thus be distinguished whether $y_{N}$ includes part of the flanges or is restricted into the web. In most practical cases, $y_{N}$ is within the web and hence, for conciseness of the paper, only this subcase is presented in detail. The normal force in the section (Figure $7(d)$ ) is:

$$
N=2 t_{w} y_{N} f_{y}-\int_{T} \sigma_{r s} d z
$$

The corresponding moment $M_{N}$ (Figure $7(\mathrm{e})$ ) is:

$$
M_{N}=M_{p}-M_{p y_{N}}-\int_{F} \sigma_{r s} z d F
$$

where $M_{p}$ is the total plastic moment resistance of the section ((Figure $\left.7(f)\right)$ and $M_{p y_{N}}$ is the plastic moment within the central part of the section which undertakes the normal forces (Figure 7(g)). If $y_{N}$ is within the web, these moments are given by:

$$
M_{p}=f_{y} W_{p l}, M_{p y_{N}}=f_{y} t_{w} y_{N}^{2}
$$

Repeating these calculations for all values of $y_{N}$, from zero to $h$, including the residual stresses, the plastic domain of the section can be defined. 


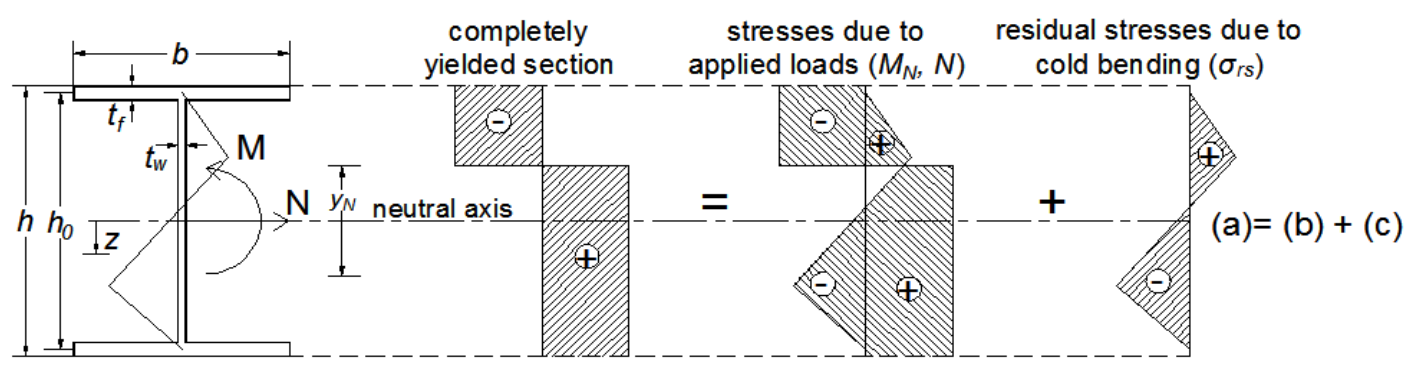

(a)

(b)

stresses due to applied normal force $(N)$

$(b)=(d)+(e)$

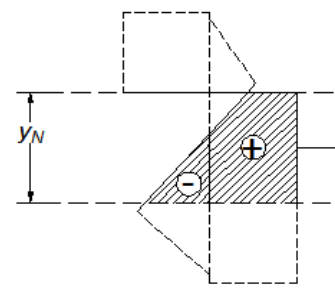

(d) (c)

stresses due to applied moment $\left(M_{N}\right)$

(e)

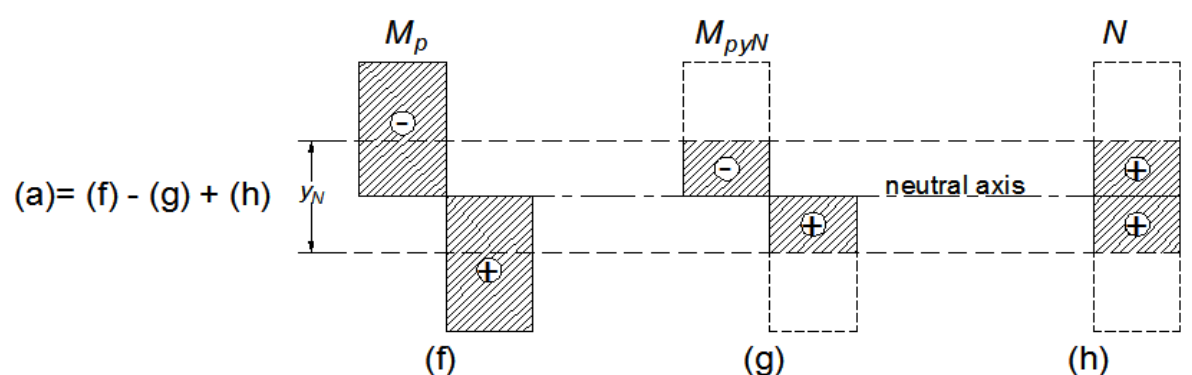

(f)

(g)

(h)

Figure 7: Decomposition of stresses in a fully yielded wide flange section under strong axis bending and normal force including the residual stresses induced by cold bending

\subsection{Numerical example}

In Figure $8(a, b)$ the elastic and plastic domains, respectively, of a HE360B section made of S235 steel subjected to combined bending moment about the strong axis and axial force are illustrated, assuming the residual stress distribution due cold bending shown in Figure 6 and following the process described in sections 3.1 and 3.2. Figure 9 shows the part of the plastic interaction diagram for compressive axial force and bending moment which tends to open the arch. For comparison, the elastic and plastic limits of the stress free section, the section with the residual stress distribution suggested by Timoshenko [20] (Figure 5) as well as the section with the residual stress distribution due to hot rolling process suggested by ECCS [10] (Figure 4) are also shown. The values of bending moment and normal force are normalized with respect to the total plastic moment capacity and the total axial capacity of the section, respectively. It is noted that the elastic domain, based on the 
residual stress distribution of Timoshenko (Figure 5), is null since at the middle of the web the stresses have already reached the yield stress $f_{y}$.

It is observed that cold bending residual stresses have a non negligible influence on the two domains, in particular the elastic one, and that this influence is different from that of the hot rolling residual stresses. It is thus considered as appropriate to carry out a parametric study for other crosssections, using only the residual stress pattern proposed by Spoorenberg et al., which is considered more reliable than the one by Timoshenko.
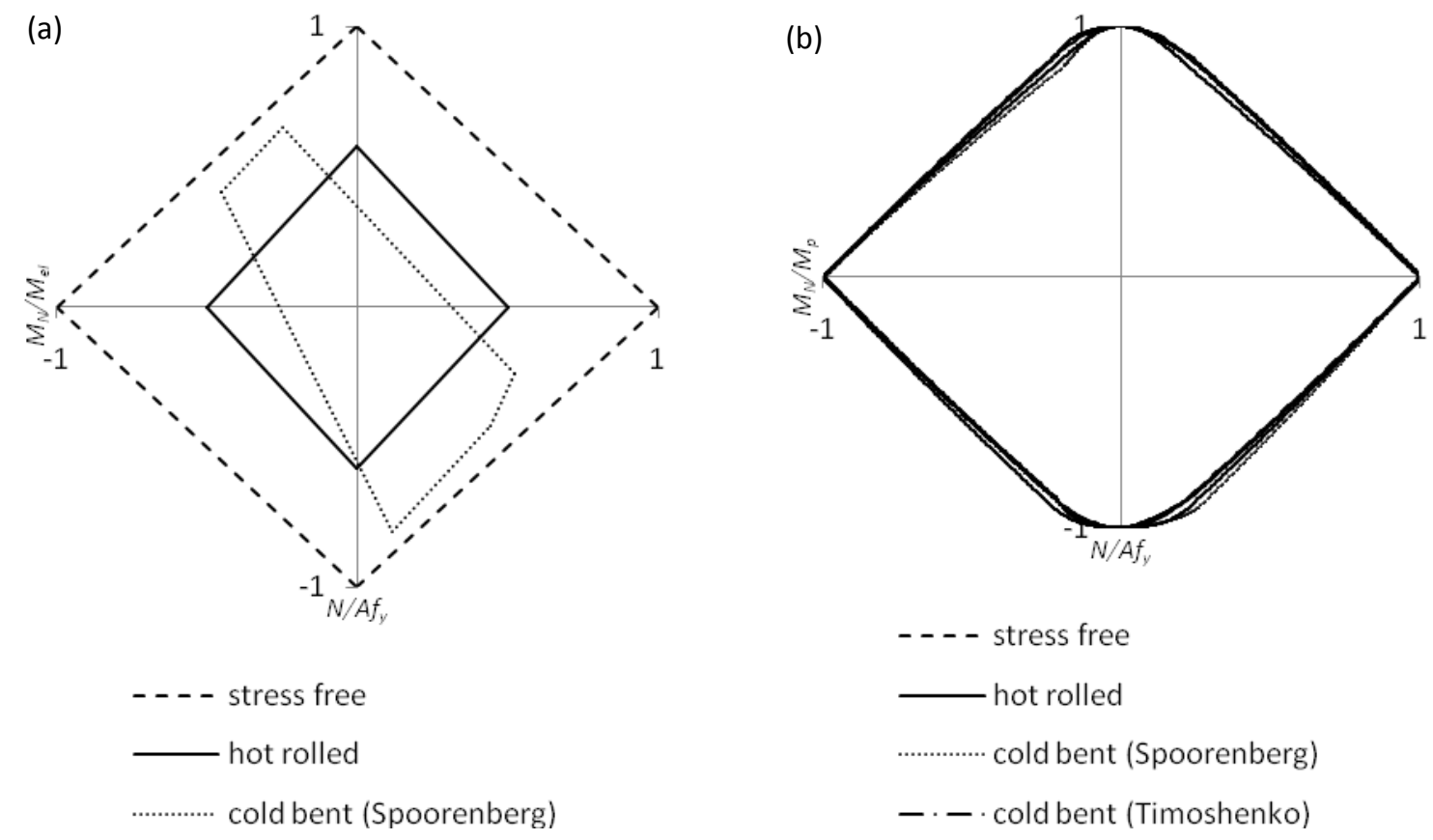

- - - stress free

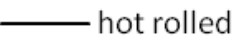

............ cold bent (Spoorenberg)

$-\cdot-$ cold bent (Timoshenko)

Figure 8: Interaction diagrams for a HE360B section, (a) Elastic domain \& (b) Plastic domain 


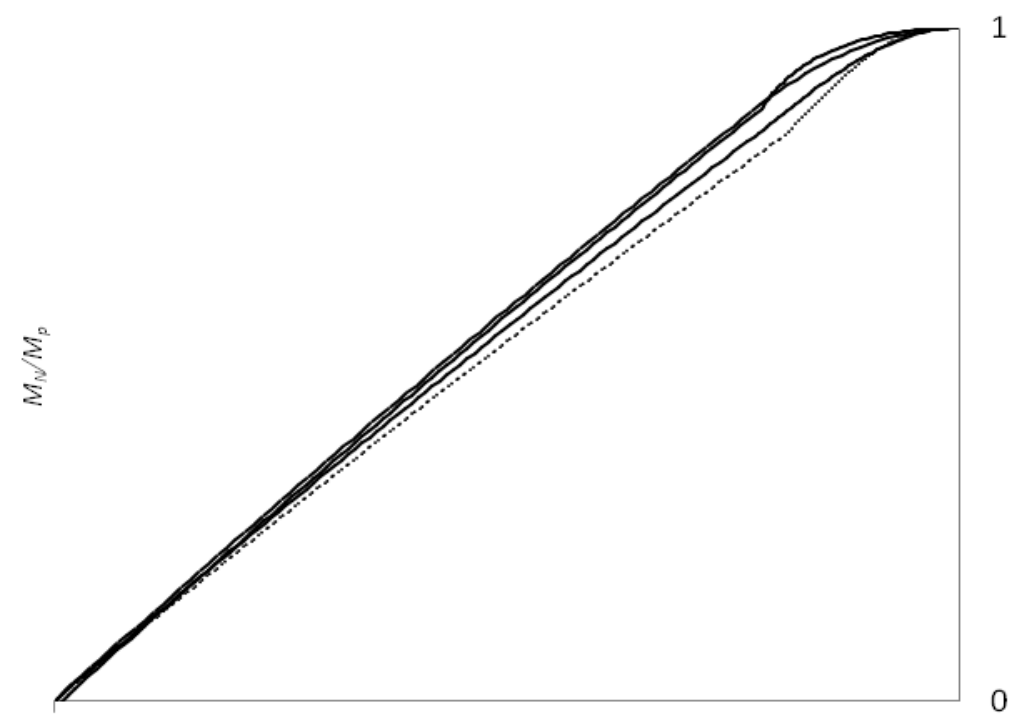

$-1$

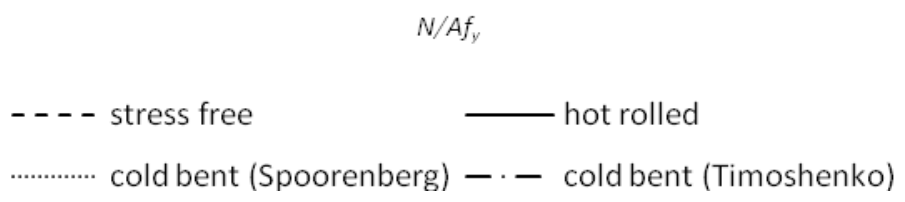

Figure 9: Interaction diagram for a HEB360 section for the plastic domain

\subsection{Parametric study}

It must be noted first that the yield stress has no influence on the elasto-plastic behavior of the section as it is linearly related with the residual stress. On the contrary, the geometric characteristics of the section do influence the behavior. This is reflected in expressions (2) for the residual stresses in the web. By changing the geometric characteristics of the section and specifically the nondimensional parameter $\beta=b t_{f} / h_{0} t_{w}$ the magnitude of the residual stresses in the web changes whereas the one in the flanges remains constant. This implies that for different sections, the influence of residual stresses is different.

For the most common sections of the European steel industry (IPE, HEA, HEB) the non-dimensional parameter $\beta$ varies considerably. In IPE sections $\beta$ is smaller varying from 0.60 (IPE600) to 0.84 (IPE80). For HEA/HEB sections this parameter is in general larger, varying from 0.59 (HEA1000) to 1.88 (HEB260). Using the procedure described in sections 3.1 and 3.2, interaction diagrams are developed for both the elastic and the plastic domain for the cases for which $\beta$ gets its extreme 
values. Figure 10 and Figure 11 illustrate the elastic and plastic domain for the lowest and highest value of parameter $\beta$, respectively. Figure 10 is for an IPE600 section which has the lowest $\beta$ value (0.60) while Figure 11 is for a HEB260 section which has the highest $\beta$ value (1.88). In the same figures, the limits of the elastic and plastic domain for these sections including the residual stresses due to hot rolling process are also included. The results can also be compared with those in Figure 8 for a HEB360 section where $\beta=1.58$.
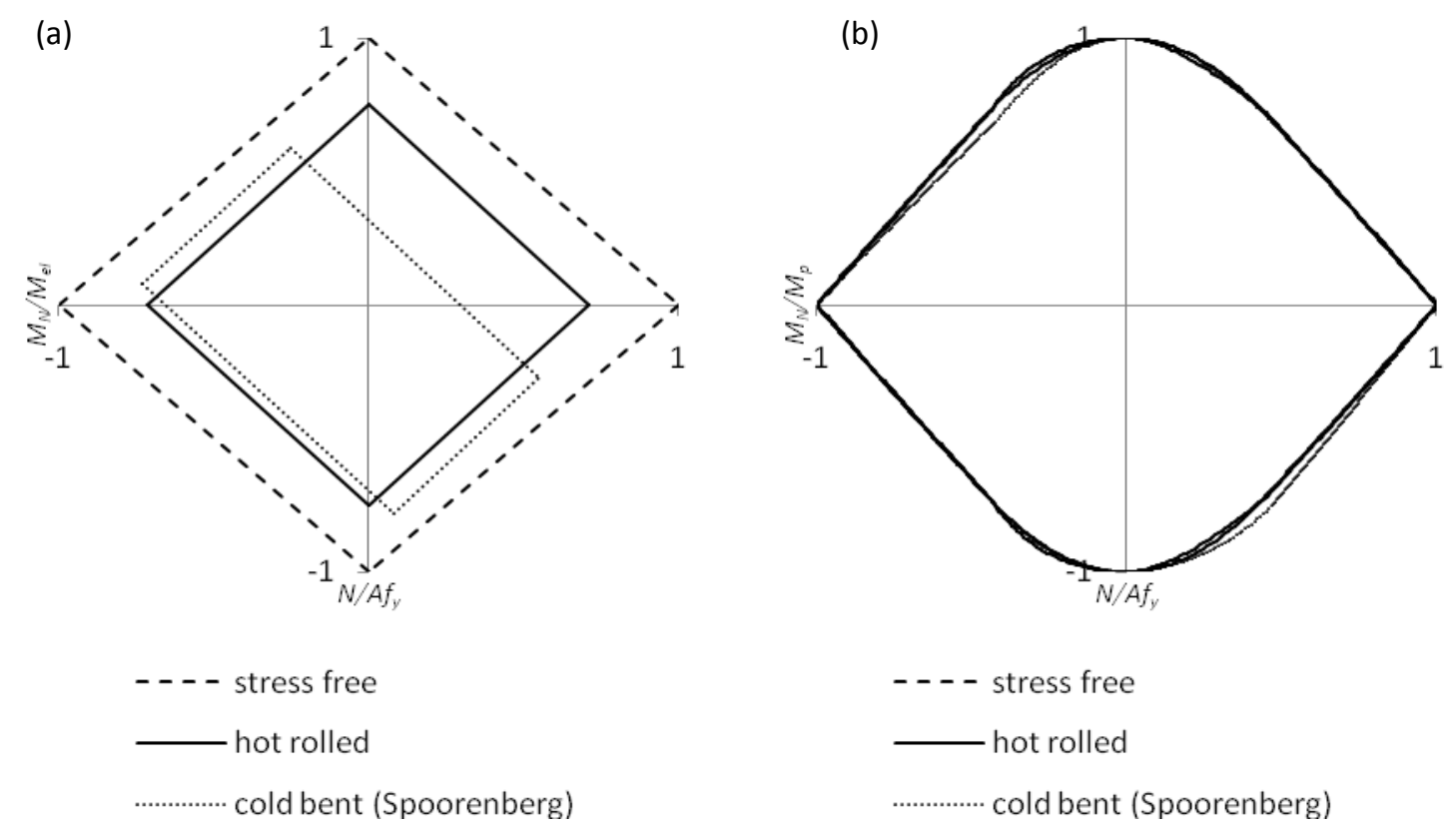

Figure 10: Interaction diagrams for IPE600 section with $\beta=0.60$, (a) Elastic domain \& (b) Plastic domain

For low values of $\beta$ the elastic diagrams are symmetric about the axis $N / A f_{y}=M / M_{p l}$ because yielding is governed by the flanges (Figure 10(a)). As the value of $\beta$ increases the elastic domain is reduced and there is no longer symmetry about the axis $N / A f_{y}=M / M_{p l}$ (Figure $8(a)$, Figure $11(\mathrm{a})$ ), as for some combinations of moment and axial force, yielding is governed by the peaks of the residual stresses at the quarters of the web (Figure 6). The elastic domain of hot rolled straight sections (Figure 8(a), Figure 10(a), Figure $11(a))$ is doubly symmetric about both the horizontal and the vertical axis as there is a symmetric residual stress distribution in the section. The corresponding limits depend on 
the aspect ratio $h / b$ of the section as for lower values of this ratio the magnitude of residual stresses is larger (Figure 4).
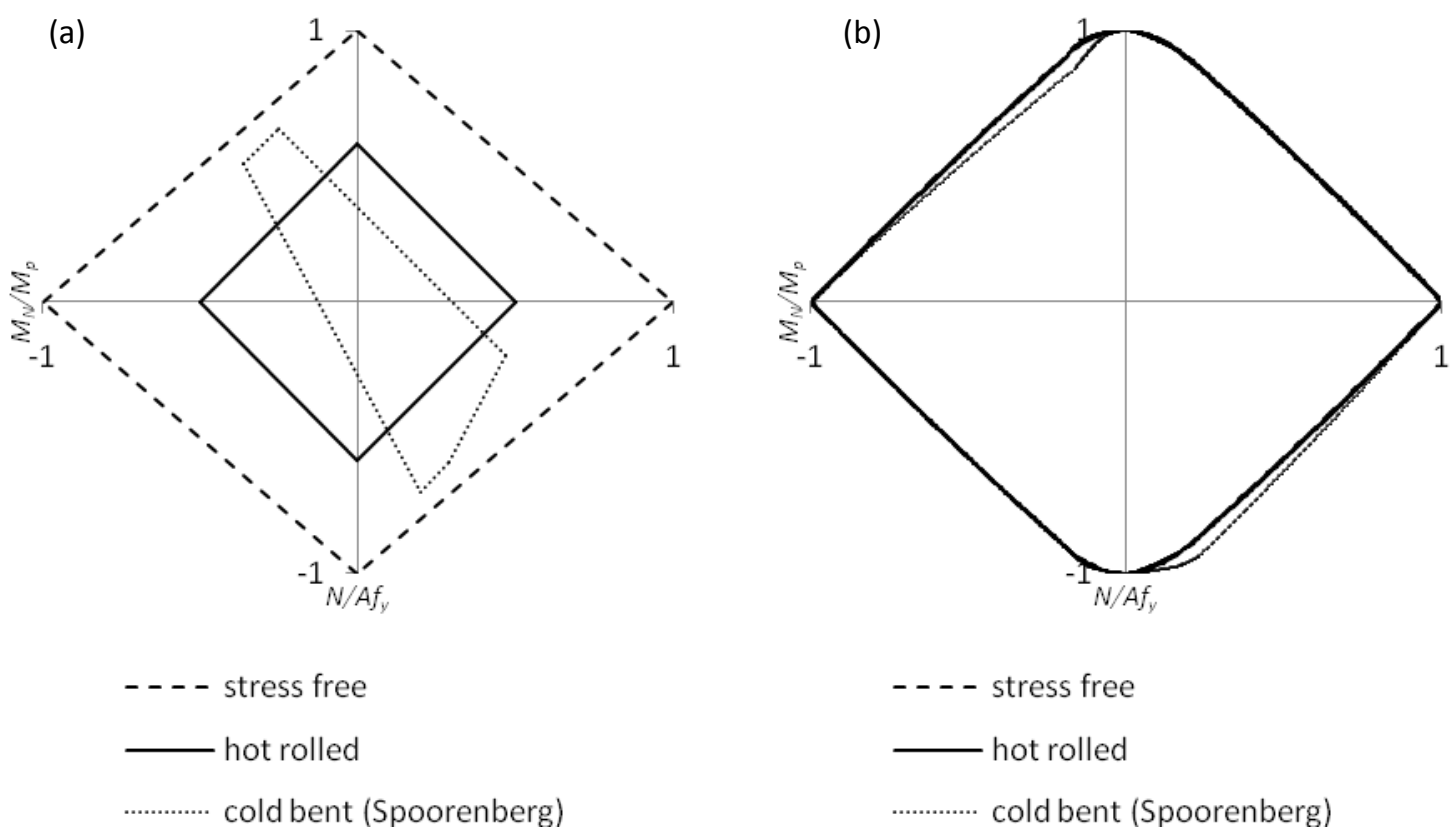

Figure 11: Interaction diagrams for HE260B section with $\beta=1.88$, (a) Elastic domain \& (b) Plastic domain

It is further observed that the plastic domain is more affected for certain combinations of axial force and bending moment. In general, the influence is larger for combinations of "tensile axial force" / "moments that tend to close the arch" and "compressive axial force" / "moments that tend to open the arch", which correspond to the common cases in engineering practice of structurally determinate arches under compression or compressed arches on soft supports. For the former combination the limits of the plastic domain increase in comparison with stress free sections, while for the latter they are reduced by the same amount. The influence increases as the value of parameter $\beta$ increases; for example, for a HEB260 section (Figure 11(b)) with $N / A f_{y}=-0.2$, $M_{N} / M_{p l}=0.90$ in a stress free section and $M_{N} / M_{p l}=0.82$ in a cold bent section. This represents a reduction of the resistance of the section of about $10 \%$. It can also be observed that the limits of the 
plastic domain are less affected by the presence of residual stresses due to hot rolling process than from the presence of residual stresses due to cold bending (Figure 8(b), Figure 10(b), Figure 11(b)). The above observations can be further quantified by comparing the differences of the capacity of the stress free section, the hot rolled section and the cold bent section for all combinations of $\left(M_{N} / M_{p l}\right) /\left(N / N_{p l}\right)$. This ratio is described by means of the angle $\gamma$, shown in Figure 12 . We denote by $\chi_{S F}, \chi_{H R}, \chi_{C B}$, the distances $O A_{S F}, O A_{H R}, O A_{C B}$, respectively, corresponding to the stress free, hot rolled and cold bent sections. These parameters are used for illustrating the differences of the capacity of stress free, hot rolled and cold bent section for certain combinations of $\left(M_{N} / M_{p l}\right) /\left(N / N_{p l}\right)$, as shown in Figure 13. The horizontal axis represents the angle $\left.\gamma=\tan ^{-1}\left[\left(M_{N} / M_{p l}\right) /\left(N / N_{p l}\right)\right]\right)$ and the vertical axis represents the percentage of difference in capacity of hot rolled and cold bent section with respect to the stress free section. It is verified that residual stresses affect the plastic capacity of cold bent sections much more than that of hot rolled sections. Moreover, for cold bent sections the influence of residual stresses reaches a reduction in capacity of up to about $10 \%$ for certain combinations of axial force and moment. It is noted that the most significant differences are observed when stresses due to axial forces have relatively high contribution to the total stress. Moreover, as the parameter $\beta$ increases, the influence on the capacity of the cold bent section increases as well.

The presented interaction diagrams can be directly used by designers to appreciate the available margins of safety of cold bent members or indirectly: for example, they could be advantageously employed for estimating the plastic collapse load of arches instead of the simple bilinear interaction curves of Spoorenberg et al. [34]. They will give a more accurate estimation with few additional computational effort. 


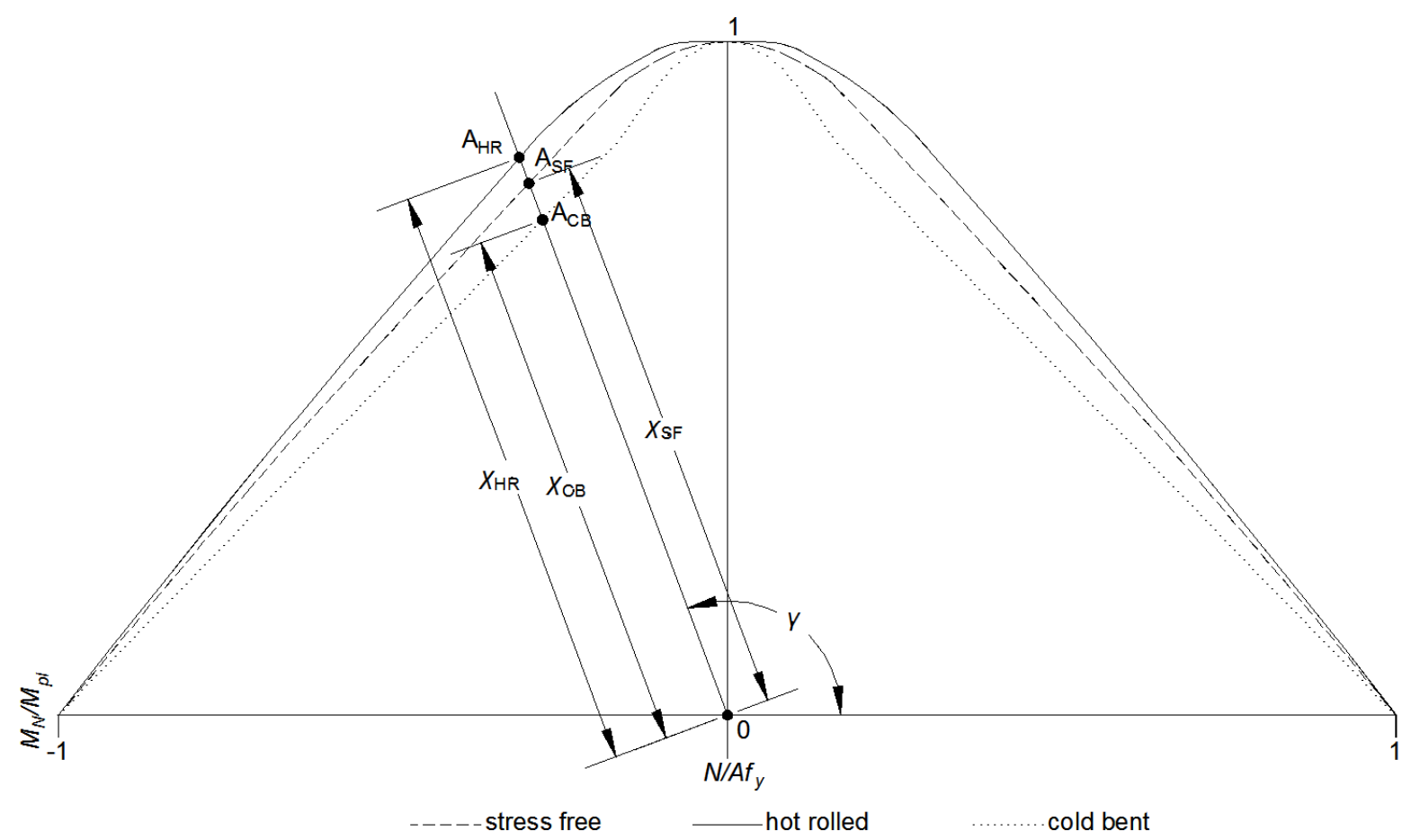

Figure 12: Definitions of characteristic parameters of the interaction diagram

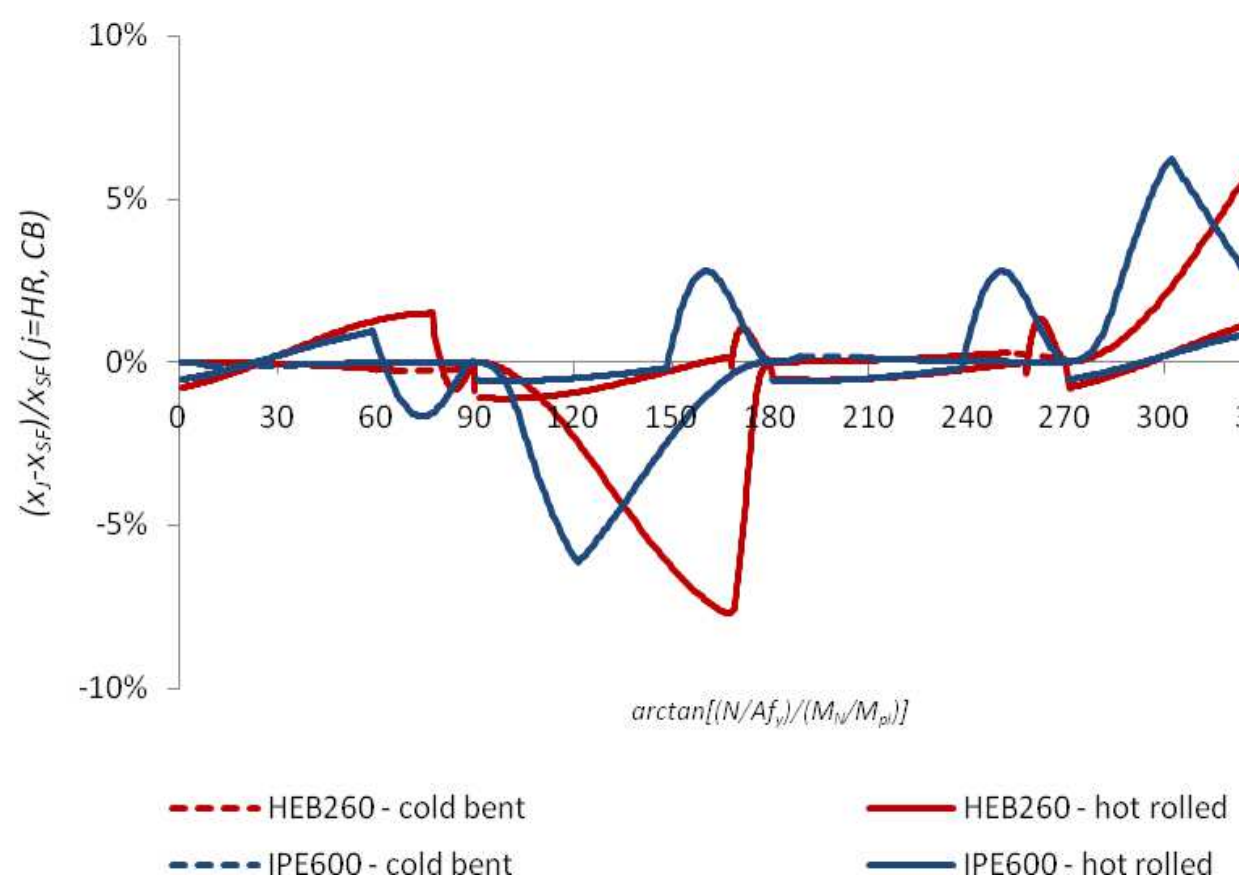

Figure 13: Difference of the capacity of stress free and cold bent sections depending on the load combination

\section{Stability of cold bent members}

In order to also evaluate the influence of residual stresses due to cold bending on curved member stability, the model of Figure 6 is here used as initial stress state for the development of buckling curves following the general methodology proposed by Beedle and Tall [4]. In order to first evaluate 
separately the influence of residual stresses on the capacity of curved members, initial imperfections and geometric non-linearities are not taken into account here, but this should be addressed in future research, before the buckling curves are actually suitable for design purposes. Nevertheless, existing work on the plastic design of arches [30-33] has already shown how hot rolling or Timoshenko like residual stresses affect the behavior of curved members. So, comparing the influence of cold bending residual stress patterns with other patterns on a member without imperfection can offer a good overview of the importance of the phenomenon.

\subsection{Definition of the elastic buckling load}

The member studied here is a perfectly circular arch, curved about its strong axis, supported by two roller supports at its ends and submitted to a uniform radial pressure, as shown in Figure 14. Inplane flexural buckling is considered, but not out-of-plane flexural or flexural torsional buckling, assuming sufficient lateral support of the arch along its length. According to these hypotheses, the arch is under pure compression in the pre-buckling phase and the normal force $N$ in the arch is related to the radial pressure $q$ through the curvature radius $R$ by:

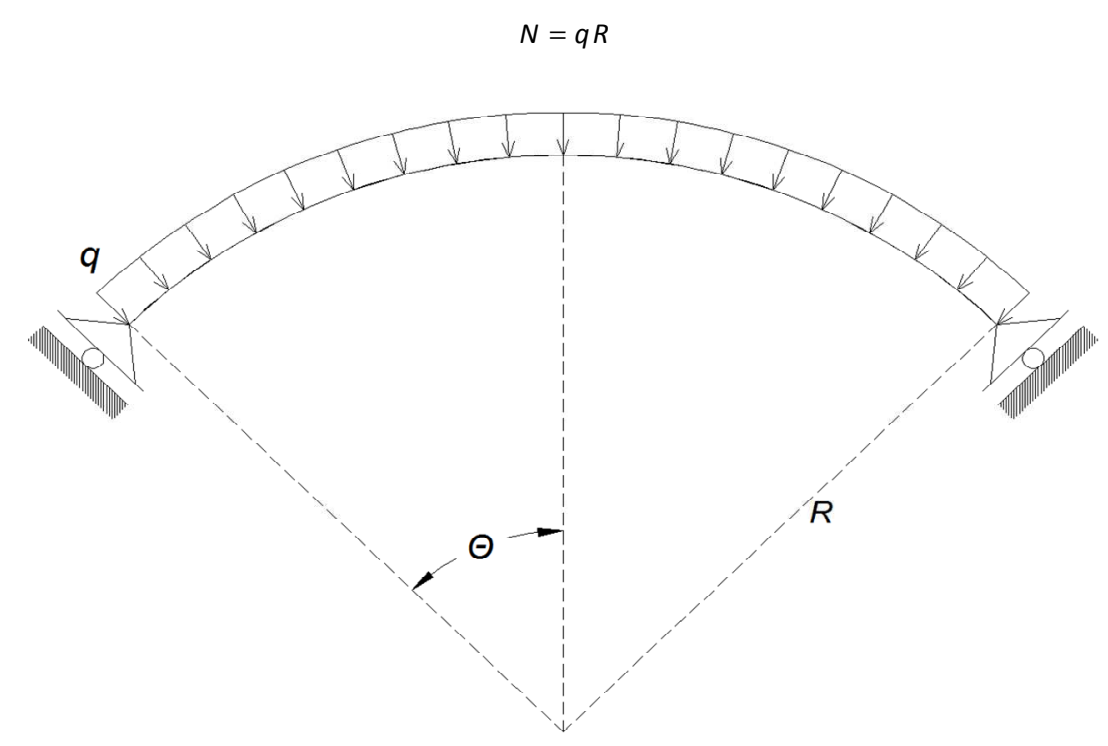

Figure 14: Geometry and loading around arch 
The arch will thus buckle if the actual compression $N$ exceeds the first critical buckling load. An analytical expression of the buckling loads can be found in [31]. It is distinguished between shallow and high arches, the first ones having angle $\theta$ such that $\left(2 \theta<90^{\circ}\right)$ and being more sensitive to the member extensibility and axial deformation. Hence, for pinned high arches, the first critical in-plane buckling load $N_{c r}$ is anti-symmetric and given by:

$$
N_{c r, h, 1}=\frac{\pi^{2} E I}{(R \theta)^{2}}
$$

$E l$ is the bending stiffness along the major principal axis and $R \theta$ represents the half length of the arch. For shallow arches, the type of buckling depends on the slenderness $\lambda$ about the major principal axis defined by:

$$
\lambda=\frac{R}{r} \theta^{2}, r=\sqrt{I / A}
$$

So, if $\lambda>9.38$, then the first buckling is anti-symmetric:

$$
N_{c r, s, 1 \alpha} \approx\left(0.26+0.74 \sqrt{1-0.63 \frac{\pi^{4}}{\lambda^{2}}}\right) N_{c r, h, 1}
$$

while if $3.88<\lambda \leq 9.38$, then the first buckling is symmetric:

$$
N_{c r, s, 1 b} \approx\left(0.15+0.006 \lambda^{2}\right) N_{c r, h, 1}
$$

It must be outlined here that, for arches, the slenderness $\lambda$ depends on the ratio between the radius of curvature of the member, the included angle of the arch and the gyration radius. The slenderness parameter hence combines geometrical aspects of the arch form with inertia aspects of the cross section, which both influence the critical behavior of the member.

\subsection{Definition of the plastic buckling load}

For evaluating the plastic buckling load, one has to take into account that, for a given normal force $N$ lower that the plastic capacity of the section $\left(N<N_{p l}=f_{y} A\right)$, the section may have partly yielded and that therefore the bending stiffness of the member in expressions (8) to (11) has to be reduced. The general methodology consists thus in supposing a certain level of normal force, then determining the yielded parts of the section and calculating the bending stiffness of the remaining elastic parts and 
finally deducing the maximum allowable slenderness $\lambda$ associated with the given normal force. If the material is assumed to be elastic perfectly plastic, then the stiffness of the yielded parts of the cross section is null.

Thus, it is first supposed that a uniform compressive stress $\sigma_{u}$ is applied to a section having residual stresses induced by cold bending. Then, assuming that the material is elastic perfectly plastic, the effective stress $\sigma_{\text {eff }}$ in the section is evaluated:

$$
\begin{array}{ll}
\sigma_{\text {eff }}=f_{y} & \text { if } \sigma_{r s}+\sigma_{u} \geq f_{y} \\
\sigma_{\text {eff }}=\sigma_{r s}+\sigma_{u} & \text { if } \sigma_{r s}+\sigma_{u}<f_{y}
\end{array}
$$

By integrating the effective stress $\sigma_{\text {eff }}$ over the entire section, the associated normal force $N_{\text {eff }}$ is calculated:

$$
N_{\text {eff }}=\int_{A} \sigma_{e f f} d A
$$

The corresponding average stress is thus given by:

$$
\sigma_{\text {avg }}=\frac{N_{\text {eff }}}{A}
$$

In the following, these values of average stress $\sigma_{\text {avg }}$ and normal force $N_{\text {eff }}$ are used as reference levels to characterize the critical elasto-plastic slenderness of the curved member. Hence, based on the effective stress (12), the inertia of the elastic parts of the section about the major principal axis is evaluated:

$$
I_{e l}=\int_{A_{e l}} y^{2} d y d z, A_{e l}=\left\{y, z / \sigma_{e f f}(y, z)<f_{y}\right\}
$$

For this level of normal force $N_{\text {eff, }}$ the modified slenderness $\bar{\lambda}$ of the elasto-plastic member about the major principal axis is then given by:

$$
\bar{\lambda}=\frac{R \theta^{2}}{r_{e l}}, r_{e l}=\sqrt{\frac{I_{e l}}{A}} \Leftrightarrow \bar{\lambda}=\lambda \sqrt{\frac{I}{I_{e l}}}
$$

Introducing then the inertia of the elastic parts (15) in expressions (8) to (11) of the buckling loads and using the modified slenderness (16), one finds expressions of the plastic buckling loads which depend on the included angle $\theta$ of the member, its radius $R$ and on the applied average stress: 


$$
\begin{gathered}
\bar{N}_{c r, h, 1}=\frac{\pi^{2} E I_{e l}}{(R \theta)^{2}} \\
\bar{N}_{c r, s, 1 a} \approx\left(0.26+0.74 \sqrt{1-0.63 \frac{\pi^{4}}{\bar{\lambda}^{2}}}\right) \bar{N}_{c r, h, 1} \text { for } \bar{\lambda}>9.38 \\
\bar{N}_{c r, s, 1 b} \approx\left(0.15+0.006 \bar{\lambda}^{2}\right) \bar{N}_{c r, h, 1} \text { for } 3.88<\bar{\lambda} \leq 9.38
\end{gathered}
$$

Varying the included angle $2 \theta$ for a given value of the radius $R$ of the arch the minimum value $\theta_{\min }$ for which the elasto-plastic in-plane buckling load is equal to the applied normal force $\left(N_{c r, s, 1, a}=N_{\text {eff }}\right)$ is obtained. The maximum allowable slenderness for that particular radius and particular level of normal force will hence be given by:

$$
\bar{\lambda}_{\max }=\frac{R \theta_{\min }^{2}}{r_{e l}}, N_{c r, s, 1 a}\left(\theta_{\min }\right)=N_{e f f}
$$

Thus, the corresponding slenderness $\lambda$ is given by:

$$
\lambda=\bar{\lambda}_{\max } \sqrt{\frac{I_{e l}}{l}}
$$

\subsection{Buckling curves for cold bent members}

Plotting for a given radius the variation of the slenderness with the applied average stress gives the desired buckling curve for the elasto-plastic buckling of perfectly circular cold bent members with hinged supports submitted to uniform radial pressure. Typical buckling curves of such cold bent members are shown in Figure 15 to Figure 17. It is noted that all buckling curves shown are developed for a range of slenderness values which correspond to an included angle for the arch of $0^{\circ}<2 \theta \leq 180^{\circ}$, in accordance with most practical cases.

In Figure 15 a comparison of the influence on the buckling resistance of the different residual stress models is shown for a HEB360 section and a radius of curvature $R=10 \mathrm{~m}$. Comparing the influence of the hot-rolled residual stress distribution [10] (Figure 4) with the one of the cold bent member [22] (Figure 6), it can be observed that the influence of cold bending is larger for slenderness values up to 110. For values larger than this, the influence due to hot rolling process is slightly larger. Using the residual stress model for cold bent members proposed by Timoshenko [20] (Figure 5), the buckling 
curve does not have a smooth shape due to the uniform residual stress distributions in the flanges. Its influence on the resistance of such members is larger for values of slenderness up to about 100. For values larger than 100, the influence of the residual stress pattern of Figure 6 is larger. Similar observations were made for other cross-sections and other curvature radius.

In Figure 16 the buckling curves of a HEB260 $(\beta=1.88)$ and an IPE270 $(\beta=0.8)$ section are shown for a radius $R=10 \mathrm{~m}$. It is noted that both sections have the same radius of gyration $(r=11.22 \mathrm{~cm})$. The buckling curve of the stress free case is also shown for comparison. It is observed that the residual stresses due to cold bending influence the buckling curves significantly with respect to those for the stress free members for intermediate values of slenderness. Beyond a certain value of slenderness, in this case approximately $\lambda=150$, there is no influence of residual stresses, buckling is perfectly elastic. Regarding the buckling curves for the two different cold bent sections, even though the aspect ratio $\beta$ is considerably different, its influence on the buckling resistance is practically negligible. This can be explained by the fact that $\beta$ affects only the level of the residual stresses in the web which does not have a significant contribution to elasto-plastic bending stiffness.

In Figure 17 a comparison of the influence of the curvature radius on the shape of the buckling curves is provided, both for cold bent and for stress free members. A HEB360 section is considered and the radii vary from $10 \mathrm{~m}$ to $25 \mathrm{~m}$, i.e. in a slightly wider range than the validity limits of the residual stress model $(10<R / h<40)$. It is noted that when the radius of curvature decreases, the range of slenderness for which elasto-plastic buckling occurs increases. Nevertheless, the maximum difference between the stress free member and the cold bent one is almost the same for all the radii of curvature. This is also valid for the highest average stress for which pure elastic buckling occurs which depends very little on the curving radius of the cold bent members. 


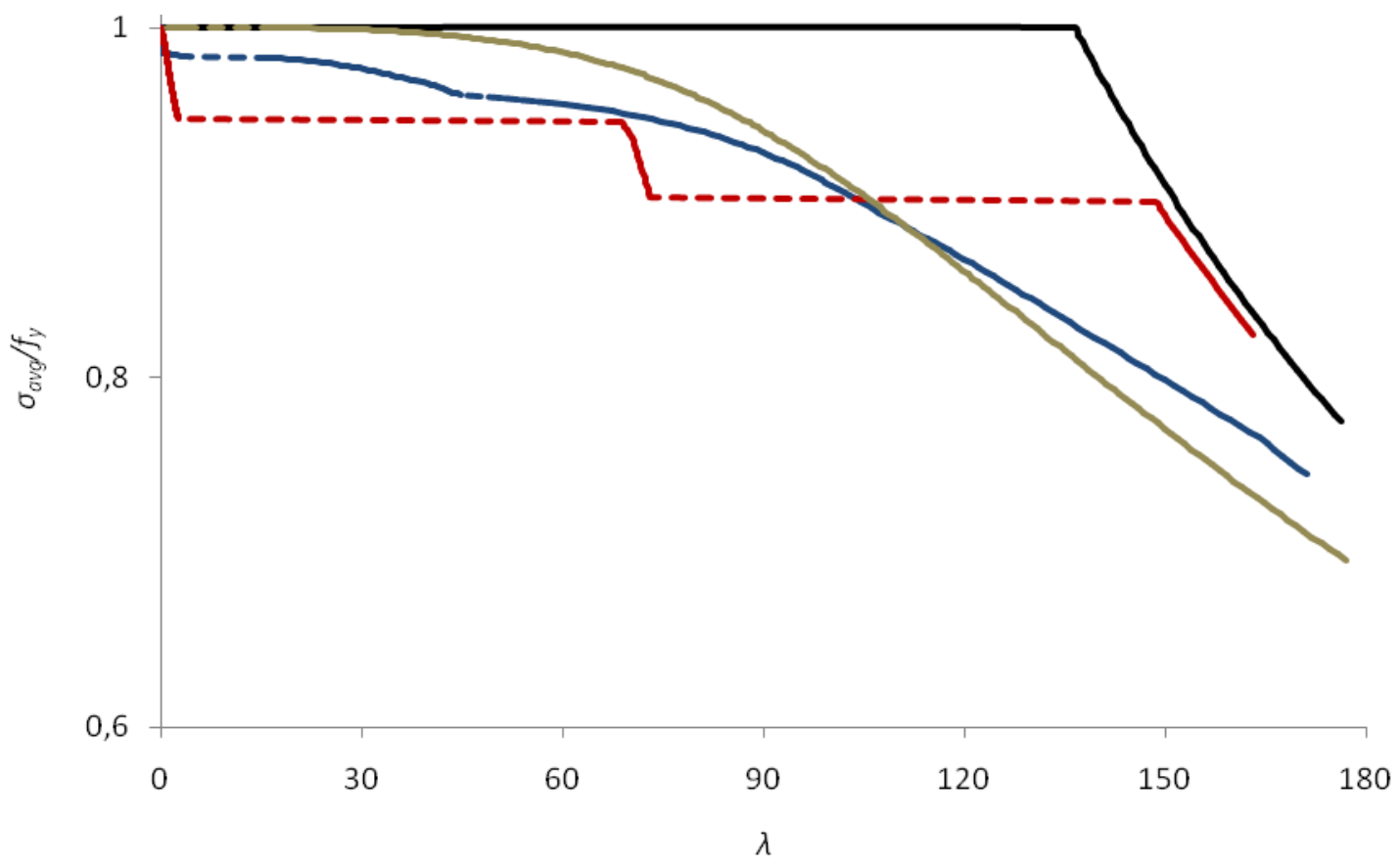

stress free - - - cold bent (Spoorenberg)

cold bent (Timoshenko) - - - hot rolled

Figure 15: Buckling curves of an arch with radius of curvature $\mathrm{R}=10 \mathrm{~m}$ for in-plane buckling with different residual stress models (HEB360)

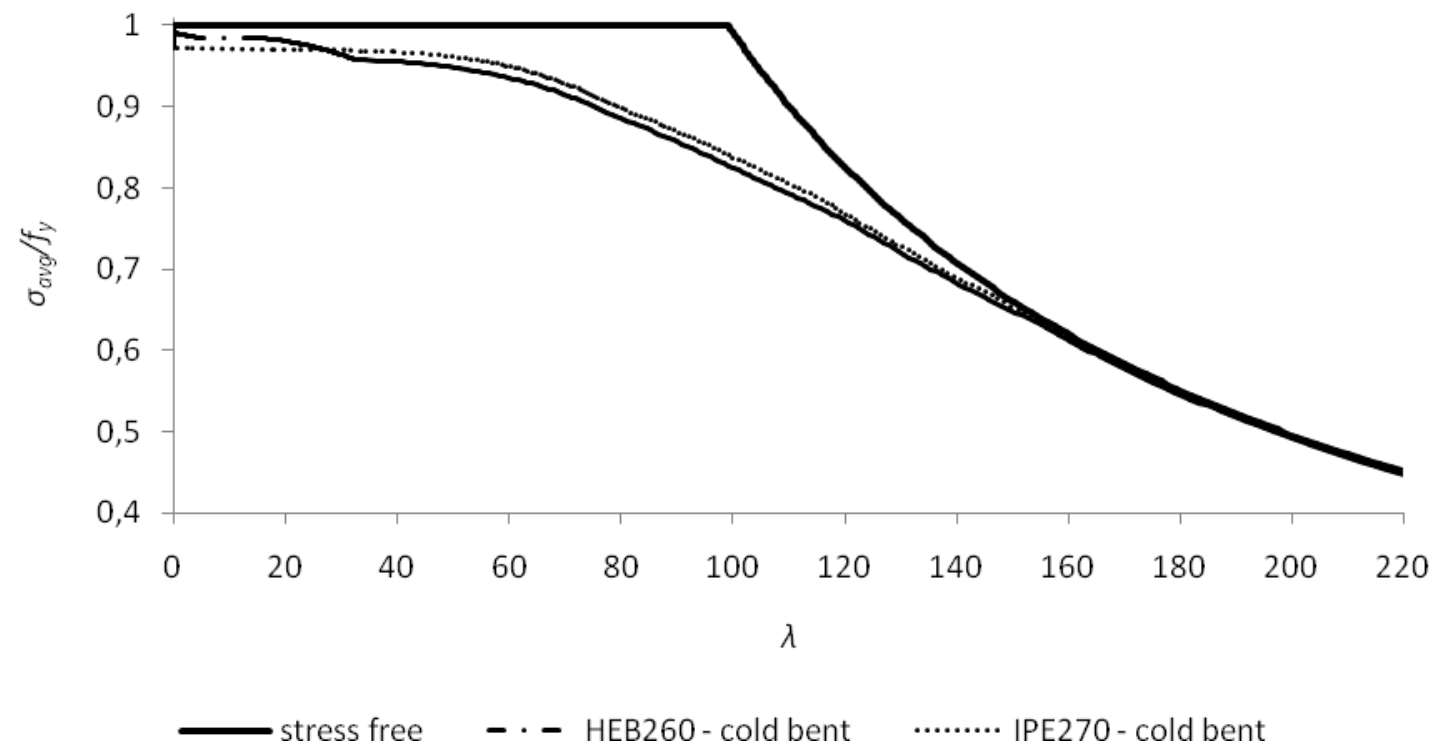

Figure 16: Buckling curves for in-plane buckling of cold bent member with radius of curvature $R=10 \mathrm{~m}$ for HEB260 and IPE270 sections 


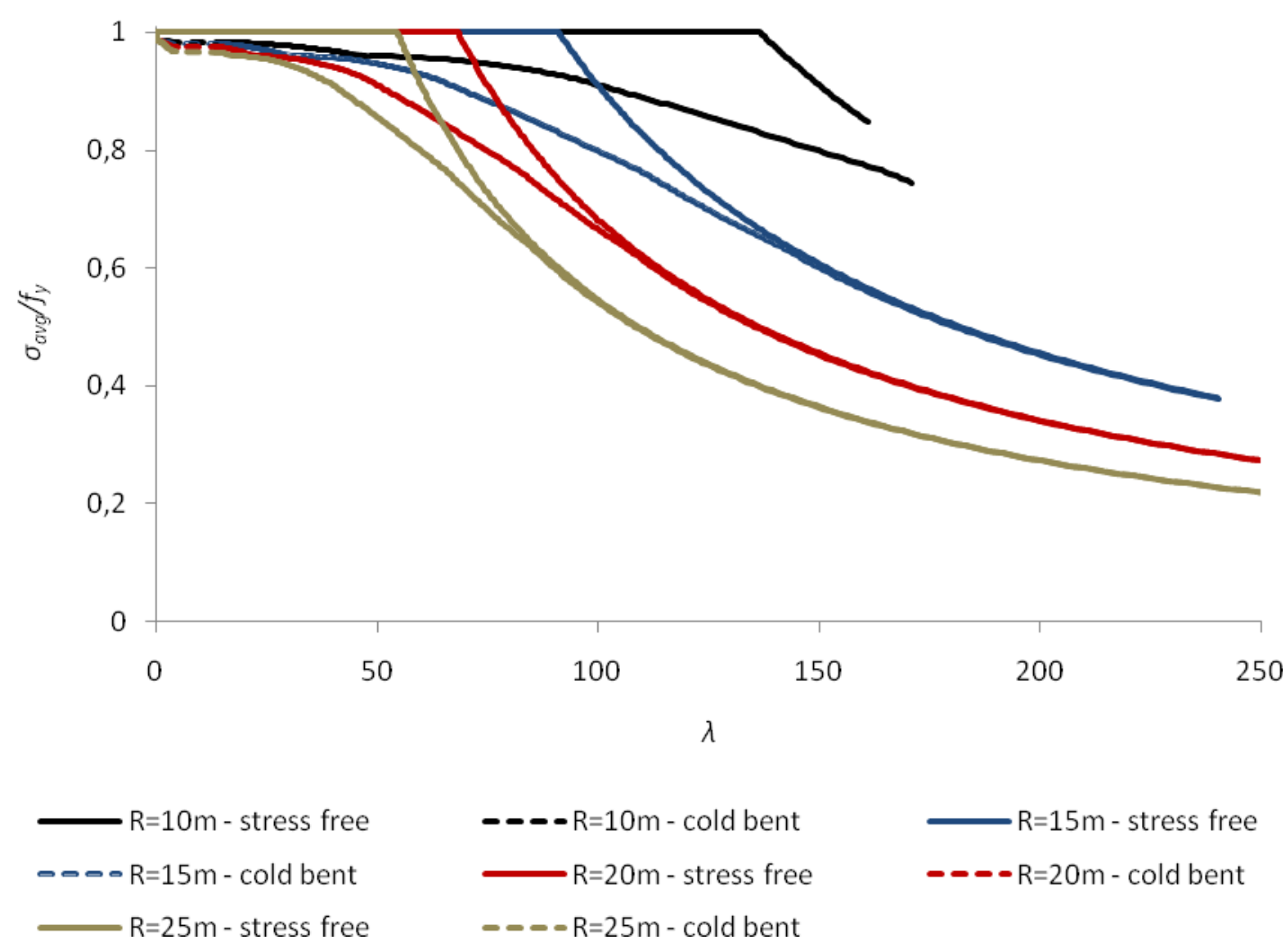

Figure 17: Influence of the radius of curvature on the in-plane buckling of cold bent members (HEB360)

\section{Summary and conclusions}

It is a well known fact that residual stresses due to hot rolling have an influence on the elasto-plastic behavior of straight members with wide flange steel sections. The purpose of this paper was hence to investigate their influence on the behavior of curved members obtained by cold bending. An upto-date review of residual stress models for curved members has hence first been presented. Then, relying on the most recent and reliable model, interaction diagrams of cold bent sections and buckling curves of perfectly circular arched members have been developed. The results of this study can be directly applied in engineering design practice to take into consideration the effects of cold bending in wide flange arches.

Since the residual stress model used in this study is not symmetric, it was shown that the residual stresses affect differently the section response depending on the type of loading (positive or negative bending moments and tensile or compressive normal forces). The elastic domain of curved 
sections is significantly reduced due to the presence of residual stresses. The plastic limit of cold bent sections is reduced by approximately $10 \%$ for some combinations of loading involving compression and opening bending moments. A safety margin of this magnitude seems thus reasonable for such sections. It was also observed that the influence of residual stresses increases when the aspect ratio $\beta=b t_{f} / h t_{w}$ increases. In general, HEA and HEB sections are affected more by the presence of residual stresses than IPE sections, since the $\beta$ parameter is higher in such sections. Concerning the buckling resistance, a parametric study has been conducted to investigate the influence of the aspect ratio $\beta$ and the curving radius $R$ and to determine how it is affected by the residual stress pattern. It was concluded that residual stresses due to cold bending affect the buckling resistance of a wide flange section in a qualitatively similar way as the residual stresses due to hot rolling, however, critical stress may differ up to $\pm 5 \%$, depending on the slenderness. The nondimensional parameter $\beta$ has no significant influence on the buckling resistance of cold bent members.

This investigation led us to the conclusion that the observed differences between hot rolled straight members with wide flange section and cold bent curved members were significant enough to necessitate the development of buckling curves for curved members. Future work will thus consist of the introduction of initial imperfections and geometric non-linearities as well as non-uniform loading conditions. The investigation of the interaction between these different factors should eventually lead to the development of design buckling curves for cold bent curved members in a format compatible to existing EC3 curves.

\section{Acknowledgement}

The authors gratefully acknowledge the support of the European Community under a Marie Curie Intra-European Fellowship for Career Development (Grant agreement number 235196). 


\section{Annex 1: (nomenclature)}

\begin{tabular}{|c|c|}
\hline$A$ & Cross-section area \\
\hline$A_{e l}$ & Area of elastic portions of cross section \\
\hline$b$ & Width of the flange \\
\hline E & Young modulus \\
\hline$F$ & Cross-sectional area which undertakes $M_{N}$ \\
\hline$f_{y}$ & Yield stress \\
\hline$h$ & Height of the section \\
\hline$h_{0}$ & $h-t_{f}$ \\
\hline 1 & Major principal axis moment of inertia of the section \\
\hline lel & Major principal axis moment of inertia of elastic portions of the section \\
\hline$M_{N}$ & Plastic moment resistance with the presence of axial force $\mathrm{N}$ \\
\hline$M_{p}$ & Total plastic moment resistance of the section for bending about the major principal axis \\
\hline$M_{p y N}$ & Plastic moment within the height $\mathrm{y}_{\mathrm{N}}$ \\
\hline$N$ & Axial force \\
\hline$N_{c r, h, 1}$ & First in-plane critical buckling load for a high arch \\
\hline$N_{c r, s, 1 a}$ & Anti-symmetric in-plane buckling load of the elastic member \\
\hline$N_{c r, s, 1 b}$ & Symmetric in-plane buckling load of the elastic member \\
\hline$N_{\text {eff }}$ & Normal force after the application of $\sigma_{u}$ \\
\hline $\bar{N}_{c r, h, 1}$ & First in-plane critical buckling load of the elasto-plastic member \\
\hline $\bar{N}_{c r, s, 10}$ & Anti-symmetric in-plane buckling load of the elasto-plastic member \\
\hline $\bar{N}_{c r, s, 1 b}$ & Symmetric in-plane buckling load of the elasto-plastic member \\
\hline$R$ & Radius of curvature of the arch \\
\hline$r_{e l}$ & In-plane radius of gyration of the elastic parts of the section \\
\hline$r$ & In-plane radius of gyration \\
\hline$T$ & Cross-sectional area which undertakes $N$ \\
\hline$t_{f}$ & Flange thickness \\
\hline$t_{w}$ & Web thickness \\
\hline$W_{p l}$ & Plastic modulus \\
\hline$y_{N}$ & Height of the section that undertakes the axial force \\
\hline$z$ & Distance from the neutral axis \\
\hline$\alpha$ & Ratio between the plastic and elastic modulus or shape factor \\
\hline$\beta$ & Non-dimensional parameter $b t_{f} / h_{0} t_{w}$ \\
\hline$y$ & Angle characterizing the load combination in the interaction diagram \\
\hline $2 \theta$ & Included angle of the arch \\
\hline$\theta_{\min }$ & Included angle of the elasto-plastic arch for which buckling occurs \\
\hline$\lambda$ & In-plane slenderness of the elastic member \\
\hline $\bar{\lambda}$ & In-plane slenderness of the elasto-plastic member \\
\hline $\bar{\lambda}_{\max }$ & Maximum allowable in-plane slenderness of the elasto-plastic member \\
\hline$\sigma_{\text {avg }}$ & Average applied stress over the entire cross section \\
\hline$\sigma_{c 1}$ & Compressive residual stress due to hot rolling process in flange tips \\
\hline$\sigma_{c 2}$ & Compressive residual stress due to hot rolling process in web midst \\
\hline$\sigma_{\text {eff }}$ & Resulting stress in the cross-section after the application of $\sigma_{u}$ \\
\hline$\sigma_{r s}$ & Residual stress \\
\hline$\sigma_{t}$ & Tensile residual stress due to hot rolling process in web to flange junctions \\
\hline
\end{tabular}




$\left|\begin{array}{|ll|}\sigma_{u} & \text { Uniformly applied stress over the entire cross-section } \\ \sigma_{\text {wrc }} & \text { Compressive residual stress in the web due to cold bending } \\ \sigma_{\text {wrt }} & \text { Tensile residual stress in the web due to cold bending } \\ \chi_{S F} & \text { Characteristic radius of plastic domain in the } \gamma \text { direction of the stress free section } \\ \chi_{H R} & \text { Characteristic radius of plastic domain in the } \gamma \text { direction of the hot rolled section } \\ \chi_{C B} & \text { Characteristic radius of plastic domain in the } \gamma \text { direction of the cold bent section }\end{array}\right|$

\section{References}

[1] L.G. Brazier, On the flexure of thin cylindrical shells and other "thin" sections, Proceedings of the Royal Society of London. Series A, 116 (1927) 104-114.

[2] R. Bjorhovde, Cold bending of wide-flange shapes for construction, Engineering Journal, 43 (2006) 271-286.

[3] A.W. Huber, L.S. Beedle, Residual stress and the compressive strength of steel, Welding Journal Research Supplement, 33 (1954) 589-615.

[4] L.S. Beedle, L. Tall, Basic column strength, Transcactions of the ASCE, 127 (1962) 138-179.

[5] C. Jez Gala, Residual stresses in rolled I-sections, ICE Proceedings, 23 (1962) 361-378.

[6] E. Mas, C. Massonet, Part prise par la belgique dans les recherches experimentales de la convention europeene des associations de la construction metallique sur la flambement centriques des barres en acier doux, Acier-Stahl-Steel, 9 (1966) 393-400.

[7] M.G. Lay, R. Ward, Residual stresses in steel sections, Journal of the Australian Institute of Steel Construction, 3 (1969) 2-21.

[8] T.V. Galambos, Guide to stability design criteria for metal structures, 5 ed., John Wiley, New York, 1998.

[9] B.W. Young, Residual stresses in hot rolled members, IABSE Reports of the Working Commisions, 23 (1975) 25-38.

[10] E.-T.C.-S. Stability, T.W.G.-. System, Ultimate limit state calculations of sway frames with rigid joints, European Convention for the Constructional Steelwork (ECCS), Paris, 1984.

[11] E.-C. 8, Manual on stability of steel structures, 2 ed., European Convention for Constructional Steelwork (ECCS), 1976.

[12] Y. Fukumoto, N. Kajina, T. Aoki, Evaluation of column curves based on probabilistic concept, In Proceedings of the International Conference on Stability, (1973) 1-37.

[13] D.S. Sophianopoulos, P.G. Asteris, D. Athanasiathou, The Eefect of thermal-induced residual stresses on the elastoplastic behavior and capacity of non-slender steel I-shaped members under combined loading, Tech. Chron. Sci. J. (TCG), 1 (2005) 37-50.

[14] J. Strating, H. Vos, Computer simulation of the E.C.C.S. buckling curve using a monte-carlo method, Heron, 19 (1973) 1-38.

[15] E.C.f.S. (CEN), Compression members, in: Eurocode 3: Design of steel structures - Part 1-1: General rules and rules for buildings, 2005.

[16] A.I.o.S. Construction, Design of members for compression, in: Specification for structural steel buildings, Americal Institute of Steel Construction (AISC), Chicago, 2005.

[17] S. Komatsu, T. Sakimoto, Ultimate load carrying capacity of steel arches, Journal of the Structural Division, 103 (1977) 2323-2336.

[18] T. Sakimoto, T. Yamao, S. Komatsu, Experimental study on the ultimate strength of steel arches, Proceedings of the Japanese Society of Civil Engineers, 286 (1979) 139-149. 
[19] Y.L. Pi, L.S. Trahair, Out-of-plane inelastic buckling and strength of steel arches, Journal of Structural Engineering, 124 (1998).

[20] S.P. Timoshenko, Strength of materials: Part II: Advanced theory and problems, 2 ed., D. Van Nostrand Company, Inc, New York, 1940.

[21] R.C. Spoorenberg, H.H. Snijder, J.C.D. Hoenderkamp, Experimental investigation of residual stresses in roller bent wide flange steel sections, Journal of Constructional Steel Research, 66 (2010) 737-747.

[22] R.C. Spoorenberg, H.H. Snijder, J.C.D. Hoenderkamp, Finite element simulations of residual stresses in roller bent wide flange sections, Journal of Constructional Steel Research, 67 (2011) 3950.

[23] R.C. Spoorenberg, H.H. Snijder, J.C.D. Hoenderkamp, Proposed residual stress model for roller bent steel wide flange sections, Journal of Constructional Steel Research, 67 (2011) 992-1000.

[24] C. King, D. Brown, Design of curved steel, The Steel Construction Institute, Berkshire, 2001.

[25] C.C. Weng, R.N. White, Residual stresses in cold-bent thick steel plates, Journal of Structural Engineering, 116 (1990) 24-39.

[26] C.C. Weng, T. Pekoz, Residual stresses in cold-formed steel members, Journal of Structural Engineering, 116 (1990) 1611-1625.

[27] Z. Tan, W.B. Li, B. Persson, On analysis and measurement of residual stresses in the bending of sheet metals, International Journal of Mechanical Sciences, 36 (1994) 483-491.

[28] B.W. Young, K.W. Robinson, Buckling of axially loaded welded steel columns, The Structural Engineer, 63 (1975) 203-207.

[29] R.C. Spoorenberg, H.H. Snijder, J.C.D. Hoenderkamp, Mechanical properties of roller bent wide flange sections - Part 2: Prediction model, Journal of Constructional Steel Research, 68 (2012) 6377.

[30] N.S. Trahair, Y.L. Pi, M.J. Clarke, J.P. Papangelis, Plastic Design of Steel Arches, in: S.L. Chan, J.G. Teng (Eds.) Advances in Steel Structures (ICASS '96), Pergamon, Oxford, 1996, pp. 13-22.

[31] Y.L. Pi, M.A. Bradford, B. Uy, In-plane stability of arches, International Journal of Solids and Structures, 39 (2002) 105-125.

[32] Y.-L. Pi, M.A. Bradford, Elasto-plastic buckling and postbuckling of arches subjected to a central load, Computers \&amp; Structures, 81 (2003) 1811-1825.

[33] Y.-L. Pi, M.A. Bradford, In-plane strength and design of fixed steel I-section arches, Engineering Structures, 26 (2004) 291-301.

[34] R.C. Spoorenberg, H.H. Snijder, J.C.D. Hoenderkamp, A theoretical method for calculating the collapse load of steel circular arches, Engineering Structures, 38 (2012) 89-103.

[35] N.S. Trahair, M.A. Bradford, N. D.A., L. Gardner, The Behavior and Design of Steel Structures to EC3, 4th Edition ed., Taylor \& Francis Group, 2007. 